Research Article

\title{
Gestational diabetes mellitus (GDM) decreases butyrylcholinesterase (BChE) activity and changes its relationship with lipids
}

Larissa O. Guimarães ${ }^{1}$, Fabiana A. de Andrade ${ }^{1}$, Gleyse F. Bono ${ }^{1}$, Thaís E. Setoguchi ${ }^{1}$, Mariana B. Brandão ${ }^{1}$, Eleidi A. Chautard-Freire-Maia ${ }^{1}$, Izabella C.R. dos Santos ${ }^{2}$, Geraldo Picheth ${ }^{2}$, Ana Cristina R. de A. Faria ${ }^{3}$, Rosângela R. Réa ${ }^{3}$, Ricardo L.R. Souza ${ }^{1}$ and Lupe Furtado-Alle ${ }^{1}$

${ }^{1}$ Paboratório de Polimorfismos e Ligação, Departamento de Genética, Universidade Federal do Paraná, Curitiba, PR, Brazil.

${ }^{2}$ Laboratório de Bioquímica Clínica, Setor de Ciências da Saúde, Universidade Federal do Paraná, Curitiba, PR, Brazil.

${ }^{3}$ Unidade de Diabetes do Serviço de Endocrinologia e Metabolismo, Hospital de Clínicas, Universidade Federal do Paraná, Curitiba, PR, Brazil.

\begin{abstract}
Many conditions interfere with butyrylcholinesterase (BChE) activity, e.g., pregnancy or presence of the $B C H E$ gene variant $-116 A$ can decrease activity whereas obesity and types I and II diabetes mellitus can increase activity. In this study, we examined BChE activity, $-116 \mathrm{~A}$ and $1615 \mathrm{~A} \mathrm{BCHE}$ gene variants, and anthropometric and biochemical variables associated with diabetes in patients with gestational diabetes mellitus (GDM) and in healthy pregnant women. $\mathrm{BChE}$ activity was measured spectrophotometrically using propionylthiocholine as substrate and genotyping of the -116 and 1615 sites of the BCHE gene was done with a TaqMan SNP genotyping assay. Three groups were studied: 150 patients with GDM, 295 healthy pregnant women and 156 non-pregnant healthy women. Mean BChE activity was significantly lower in healthy pregnant women than in women from the general population and was further reduced in GDM patients. BChE activity was significantly reduced in carriers of -116A in GDM patients and healthy pregnant women. Although GDM patients had a significantly higher mean body mass index (BMI) and triglycerides than healthy pregnant women, they had lower mean BChE activity, suggesting that the lowering effect of GDM on $\mathrm{BChE}$ activity was stronger than the characteristic enhancing effect of increased $\mathrm{BMI}$ and triglycerides.
\end{abstract}

Key words: butyrylcholinesterase (BChE), gestational diabetes mellitus, $-116 \mathrm{~A}$ variant, $1615 \mathrm{~A}$ variant.

Received: April 17, 2013; Accepted: August 20, 2013.

\section{Introduction}

Human butyrylcholinesterase (BChE; EC 3.1.1.8) is a serum esterase that hydrolyzes choline esters, as well as other esters, but its physiological function is not completely known (Chatonnet and Lockridge, 1989). BChE is found in plasma, liver, neuroglia, pancreas, digestive tube wall, lung, brain, muscle, kidney and heart (Siqueira et al., 1978). Obesity (Alcântara et al., 2003; Randell et al., 2005; Iwasaki et al., 2007), hypertension (Alcântara et al., 2002), and types I and II diabetes mellitus (DM1 and DM2) (Antopol et al., 1937; Abbott et al., 1993; Pavkovic et al., 1993) have been associated with an increase in BChE activity, whereas myocardial infarction (Whittaker, 1986) and some variants of the butyrylcholinesterase ( $B C H E$ ) gene (Babao-

Send correspondence to Lupe Furtado-Alle. Department of Genetics, Biological Sciences Sector, Federal University of Paraná, Caixa Postal 19071, 81531-980 Curitiba, PR, Brazil. E-mail: lupealle@gmail.com. glu et al., 2004; Valle et al., 2006; Furtado-Alle et al., 2008) have been associated with a decrease in activity. A decrease in activity of $\sim 25 \%$ has been observed after the tenth week of pregnancy, and a reduction of $33 \%$ occurs between ten days after delivery and six weeks of age (Whittaker, 1980). Evans and Wroe (1980) measured serum BChE activity in 941 pregnant women and observed a rapid fall during the first trimester to a level that did not change significantly during the remainder of pregnancy.

Gestational diabetes mellitus (GDM) affects 3-10\% of pregnancies (Lobato, 2002) and is a risk factor for the mother and fetus (Schmidt et al., 2001). Mahmoud et al. (2006) and Omu et al. (2010) examined BChE activity in GDM and reported a significant increase in healthy pregnant women compared to GDM patients. However, the sample size was relatively small, the authors did not consider other variables that may influence $\mathrm{BChE}$ activity and they did not compare $\mathrm{BChE}$ activity between pregnant and non-pregnant women. 
Variants of the BCHE gene (3q26.1-q26.2) (Soreq et al., 1987) have been associated with DM1 and DM2 (Hashim et al., 2001; Alcântara et al., 2002, 2005; Lepienski et al., 2006; Iwasaki et al., 2007; Vaisi-Raygani et al., 2008). The K variant of the BCHE gene (SNP: G/A; rs 1803274; p.A539T; $1615 \mathrm{nt}$ ) has a frequency of $18.4 \%$ in Euro-Brazilians (Souza et al., 1998) and was originally associated with lower BChE activity. The $-116 \mathrm{~A}$ variant (SNP: G/A; rs1126680; -116 nt) is located in non-codifying exon 1 and has a frequency of $8 \%$ in Euro-descendants, with $-116 \mathrm{~A}$ being found preferentially in cis with the $\mathrm{K}$ variant (Bartels et al., 1990). Although the $\mathrm{K}$ variant was originally associated with lower BChE activity, this variant alone is not associated with a decrease in BChE activity since the $-116 \mathrm{~A}$ variant is required for this decrease (Furtado-Alle et al., 2008).

In view of the limited investigations into the physiopathology of GDM, in this study we examined BChE activity and behavior in GDM. Some of the variables that influence enzyme activity, e.g., $-116 \mathrm{~A}$ and $1615 \mathrm{~A}$ variants of the $B C H E$ gene, age, body mass index (BMI), total cholesterol, HDL cholesterol, LDL cholesterol and triglyceride levels, were also examined. To investigate variants in the regulatory region that may influence $\mathrm{BChE}$ activity, four tag SNPs were genotyped: two upstream (rs4440084 and rs2863381) and two downstream (rs7624915 and rs4387996) of the $B C H E$ gene.

\section{Materials and Methods}

\section{Subjects}

Three groups were studied: (1) 150 pregnant women with GDM, (2) 295 healthy pregnant women and (3) 156 female blood donors. The GDM group was recruited from the Diabetes Unit of the Endocrinology and Metabolism Service (SEMPR) of the Clinical Hospital at the Federal University of Paraná (UFPR) and the healthy pregnant women were recruited from the Municipal Laboratory in Curitiba. The group of female blood donors (BMI = 24.24 \pm 3.08 ; $\mathrm{n}=156$ ) was collected at HEMEPAR in Curitiba. GDM was defined based on carbohydrate intolerance and resulted in hyperglycemia that began in or was first detected during pregnancy (World Health Organization, 1999). GDM was diagnosed using the criteria of the Brazilian Diabetes Society (Sociedade Brasileira de Diabetes, 2009), based on a Brazilian study of Gestational Diabetes (Schmidt et al., 2001) and on World Health Organization criteria (World Health Organization, 2006). An initial screening of fasting glucose was done during the first appointment: fasting glucose between 85 and $109 \mathrm{mg} / \mathrm{dL}$ indicated the need for an oral glucose tolerance test (OGTT). OGTT values $>110$ and/or $140 \mathrm{mg} / \mathrm{dL}$ in fasting and postprandial conditions, respectively, confirmed GDM. Before initiating the diet, fasting glucose $\geq 110 \mathrm{mg} / \mathrm{dL}$ was again examined and another value in this range characterized GDM. The healthy pregnant women group had fasting glucose $<85 \mathrm{mg} / \mathrm{dL}$ or OGTT values $<110 \mathrm{mg} / \mathrm{dL}$ during fasting and $<140 \mathrm{mg} / \mathrm{dL}$ in the postprandial period. Patients who reported renal failure and cardiovascular disease were excluded. Blood samples and clinical and anthropometric variables were collected from GDM patients following diagnosis and before the beginning of treatment. Pregnant women with GDM and healthy controls were paired in relation to gestational age.

This study was approved by the Research Ethics Committee of the Health Science Sector of UFPR and by the Research Ethics Committee of the Municipal Health Department of the City Hall of Curitiba.

\section{Laboratory methods}

Peripheral blood samples were collected without anticoagulant in dry tubes containing a separator gel and then centrifuged; the resulting serum was stored at $-20{ }^{\circ} \mathrm{C}$. The biochemical parameters were quantified using an Architect automated system (Abbott) with Trulab calibrators and controls.

BChE activity was measured spectrophotometrically $\left(\mathrm{A}_{410 \mathrm{~nm}}\right)$ at $25^{\circ} \mathrm{C}$ using propyonilthiocoline as substrate, as described by Dietz et al. (1972) and modified by Evans and Wroe (1978).

Genomic DNA was extracted by the salting-out method (Lahiri and Nurnberger Jr, 1991) with modifications, or with a Blood Genomic Prep Mini Spin (GE Healthcare) and stored at $-20{ }^{\circ} \mathrm{C}$. All DNA samples were adjusted to a concentration of $100 \mathrm{ng} / \mu \mathrm{L}$.

Genotyping of the -116 and 1615 sites of the $B C H E$ gene (rs1126680 and rs1803274, respectively) and the four SNPs near this gene (rs4440084, rs 2863381, rs7624915 and rs4387996) was done using a TaqMan SNP genotyping kit (Applied Biosystems, reference code 27847456), performed on a Mastercycler Realplex 2 equipment (Eppendorf). To $8.5 \mu \mathrm{L}$ of reaction mix $(4.0 \mu \mathrm{L}$ of TaqMan Universal PCR Master Mix, $0.3 \mu \mathrm{L}$ of specified TaqMan SNP genotyping kit and $4.2 \mu \mathrm{L}$ of ultrapure water) was added $2 \mu \mathrm{L}(20 \mathrm{ng} / \mu \mathrm{L})$ of DNA. The amplification involved 45 cycles of $2 \mathrm{~min}$ at $50^{\circ} \mathrm{C}, 10 \mathrm{~min}$ at $95^{\circ} \mathrm{C}$ and $15 \mathrm{~s}$ at $95{ }^{\circ} \mathrm{C}$ intercalated with $60 \mathrm{~s}$ at $60{ }^{\circ} \mathrm{C}$.

\section{Statistical analysis}

Frequency distributions, means $\pm \mathrm{SE}$, variances and the $t$-test were calculated using Statistica for Windows software (StatSoft, Inc.) and a 5\% significance level was adopted. Data normality was tested by the Shapiro-Wilk normality test. Arlequin 2000 (Schneider et al., 2000) was used to estimate the haplotypes and Bonferroni's correction was applied for comparisons between groups. Allelic and genotypic frequencies were obtained by direct counting and compared between groups via the chi-square test using Clump (Sham and Curtis, 1995). Pearsons correlation anal- 
ysis between $\mathrm{BChE}$ activity and variables related to GDM was done using Statistica for Windows software. Regression analysis was done using SPSS for Windows (SPSS Inc.) to verify whether $\mathrm{BChE}$ activity was dependent on variables related to GDM and $B C H E$ gene variants.

\section{Results}

\section{Clinical and anthropometric features}

Table 1 shows the mean \pm SD and variances of age, BMI and clinical data for pregnant women (GDM and controls), along with their $t$ and $F$ test values. The variables age, BMI, total cholesterol, HDL cholesterol and triglycerides, differed significantly between the groups.

\section{BChE activity}

Table 2 summarizes the results for $\mathrm{BChE}$ activity in women with GDM and controls. BChE activity was signifi- cantly higher in healthy pregnant women than in women with GDM $(2.83 \pm 0.89 \mathrm{KU} / \mathrm{L}$ vs. $2.26 \pm 0.59 \mathrm{KU} / \mathrm{L}$; $\left.t=-7.06, \mathrm{p}=6.66 \times 10^{-12}\right)$, but was significantly lower in both groups than in the general population sample (4.68 \pm $1.51 \mathrm{KU} / \mathrm{L} ; t=14.06$ and $\mathrm{p}=0.00$ for healthy pregnant women; $t=18.54$ and $\mathrm{p}=0.00$ for GDM).

In the GDM group, the correlation coefficients (r) between BChE activity and BMI and BChE activity and LDL cholesterol were $0.18(\mathrm{p}<0.05)$ and $-0.19(\mathrm{p}<0.05)$, respectively. In pregnant women of the control group, total cholesterol, HDL cholesterol and triglyceride levels were negatively correlated with $\mathrm{BChE}$ activity $(\mathrm{r}=-0.12$; $r=-0.49$ and $r=-0.19$, respectively, $p<0.05$ ). Since BChE activity differed between patients and controls, a forward step-wise multiple regression analysis was done in which BChE activity was the dependent variable and GDM/pregnant women without the disease, age, BMI, total cholesterol, LDL cholesterol, HDL cholesterol, triglycerides,

Table 1 - Age, body mass index and clinical features of healthy pregnant women (controls) and pregnant women with gestational diabetes mellitus (GDM).

\begin{tabular}{|c|c|c|c|c|c|c|}
\hline & \multicolumn{2}{|l|}{ GDM $(N=150)$} & \multicolumn{4}{|c|}{ Healthy pregnant women $(\mathrm{N}=295)$} \\
\hline & Mean \pm SD & $S^{2}$ & Mean \pm SD & $S^{2}$ & $t(\mathrm{p})$ & $F(\mathrm{p})$ \\
\hline Age (years) & $31.8 \pm 6.1$ & 37.38 & $25.0 \pm 6.3$ & 39.14 & $10.79\left(2.97 \times 10^{-24}\right)^{*}$ & $1.05(0.76)$ \\
\hline $\operatorname{BMI}\left(\mathrm{kg} / \mathrm{m}^{2}\right)$ & $33.4 \pm 6.1$ & 37.37 & $25.1 \pm 4.6$ & 21.39 & $15.77(<0.00001)^{*}$ & $1.75\left(7.3 \times 10^{-5}\right)^{*}$ \\
\hline Total cholesterol $(\mathrm{mg} / \mathrm{dL})^{1}$ & $226.5 \pm 47.5$ & 2252.58 & $201.5 \pm 53.2$ & 2830.01 & $4.49\left(9 \times 10^{-6}\right)^{*}$ & $1.26(0.15)$ \\
\hline LDL cholesterol (mg/dL) & $125.8 \pm 42.7$ & 1823.94 & $123.9 \pm 43.3$ & 1870.95 & $0.39(0.69)$ & $1.03(0.88)$ \\
\hline HDL cholesterol (mg/dL) & $56.8 \pm 15.1$ & 227.13 & $53.1 \pm 16.1$ & 258.37 & $2.32(0.02)^{*}$ & $1.14(0.39)$ \\
\hline Tryglycerides (mg/dL) & $225.3 \pm 73.1$ & 5345.00 & $122.6 \pm 57.5$ & 3303.32 & $15.29(<0.00001)^{*}$ & $1.62(0.001)^{*}$ \\
\hline Fasting glucose (mg/dL) & $94.2 \pm 23.1$ & 534.04 & $82.2 \pm 6.8$ & 45.67 & $8.23\left(2.16 \times 10^{-15}\right)^{*}$ & $11.69(<0.00001)^{*}$ \\
\hline Fasting OGTT ${ }^{2}$ & $99.1 \pm 16.7$ & 278.03 & - & - & - & - \\
\hline Post-prandial OGTT & $165.8 \pm 33.0$ & 1087.53 & - & - & - & - \\
\hline
\end{tabular}

BMI - body mass index. OGTT - oral glucose tolerance test $75 \mathrm{~g}$. $S^{2}$ - variance. ${ }^{1}$ The total cholesterol, LDL cholesterol and triglyceride levels were available for 122 patients with GDM whereas the HDL cholesterol values were available for 139 patients with GDM. BMI values were available for 142 patients with GDM; ${ }^{2}$ OGTT with normal values $<110$ and $140 \mathrm{mg} / \mathrm{dL}$ in fasting and post-prandial $(2 \mathrm{~h}$ after ingestion) conditions, respectively. The OGTT was done in 142 patients. The $t$ values for Student's $t$-test (comparison of means) and the $f$ values for the F-test (equality of two variances) are shown. $* \mathrm{p}<0.05$.

Table 2 - Butyrylcholinesterase activity (KU/L) in women with gestational diabetes mellitus (GDM), healthy pregnant women (controls) and female blood donors.

\begin{tabular}{lccc}
\hline Groups & Mean $\pm \mathrm{SD}(\mathrm{KU} / \mathrm{L})$ & $S^{2}$ & $\mathrm{RV}$ \\
\hline GDM $(\mathrm{N}=150)$ & $2.26 \pm 0.59$ & 0.36 & $0.67-4.39$ \\
Healthy pregnant women $(\mathrm{N}=250)$ & $2.83 \pm 0.89$ & 0.79 & $0.76-5.56$ \\
Female blood donors $(\mathrm{N}=156)$ & $4.68 \pm 1.51$ & 2.28 & $0.16-11.3$ \\
\hline Comparison between the groups & & $t(\mathrm{p})$ & $F(\mathrm{p})$ \\
\hline & GDM $v$ s. healthy pregnant women & $-7.06\left(6.66 \times 10^{-12}\right)^{*}$ & $2.22\left(1.22 \times 10^{-7}\right)^{*}$ \\
& GDM $v s$. female blood donors & $18.54(0.00)^{*}$ & $6.41\left(1.25 \times 10^{-26}\right)^{*}$ \\
& Healthy pregnant women x female blood donors & $14.06(0.00)^{*}$ & $2.89\left(5.51 \times 10^{-15}\right)^{*}$ \\
\hline
\end{tabular}

$\mathrm{RV}$ - range of variation. $S^{2}$ - variance. The $t$ values for Student's $t$-test (comparison of means) and the $f$ values for the F-test (equality of two variances) are shown. ${ }^{*} \mathrm{p}<0.05$. 
$-116 A$ and $1615 A$ variants of the $B C H E$ gene and the four tag SNPs were the independent variables. This analysis showed that BChE activity was significantly dependent on the sample group - GDM/pregnant women without the disease $(\beta=0.198, \mathrm{p}=0.00152)$ and presence of the $B C H E$ gene variant $-116 A(\beta=-0.166, p=0.0000812)$. In the patients and control group, $\mathrm{BChE}$ activity was significantly higher in pregnant women homozygous for the usual allele $(-116 G)$ than in heterozygous individuals $(-116 A G)(2.31 \pm$ $0.61 \mathrm{KU} / \mathrm{L} v s .1 .93 \pm 0.42 \mathrm{KU} / \mathrm{L} ; t=2.53, \mathrm{p}=0.01$, for $\mathrm{GDM}$; and $2.88 \pm 0.88 \mathrm{KU} / \mathrm{L} v s .2 .39 \pm 0.81 \mathrm{KU} / \mathrm{L} ; t=2.96$, $\mathrm{p}=0.003$, for healthy pregnant women, respectively).

\section{Frequencies of -116 and 1615 site variants}

The genotypic frequencies for both sites were in Hardy-Weinberg equilibrium and did not differ between the GDM patients and controls $\left(\chi^{2}=1.92, \mathrm{p}=0.38\right.$ for the -116 site and $\chi^{2}=0.56 ; p=0.75$ for the 1615 site). The frequency of the $-116 \mathrm{~A}$ allele did not differ between the GDM patients and controls $(7.69 \pm 0.09 \%$ vs. $5.76 \pm 0.04 \%$, respectively, $\left.\chi^{2}=1.20, \mathrm{p}=0.27\right)$. The $1615 \mathrm{~A}$ allele frequency did not differ between the GDM patients and controls $\left(17.13 \pm 0.13 \%\right.$ vs. $17.12 \pm 0.06 \%$, respectively, $\chi^{2}=0.00$, $\mathrm{p}=0.99)$.

\section{Haplotype frequencies}

For haplotype inferences, in addition to the $-116 \mathrm{~A}$ and $1615 A$ variants, the four SNPs close to the $B C H E$ gene were also included (rs4440084, rs2863381, rs7624915 and rs4387996). The genotype frequencies of these four SNPs were in Hardy-Weinberg equilibrium and the allele and genotype frequencies did not differ between GDM patients and healthy pregnant women. After the application of Bonferroni's correction there was no significant difference in the haplotype frequencies between healthy pregnant women and pregnant women with GDM.

\section{Discussion}

Pregnancy is associated with physiological changes that include an increase in caloric intake, greater accumulation of fat mass and a progressive increase in insulin resistance (Tham et al., 2009). Towards the end of pregnancy, the insulin resistance approaches that of DM2 patients. Insulin resistance during pregnancy most likely reflects a combination of maternal body fat excess and placental hormone effects that reduce the sensitivity to insulin. Resistance to insulin is normally compensated for by an increase in insulin secretion by pancreatic $\beta$-cells. Hyperglycemia in GDM results from inadequate insulin supplement to the tissues (Buchanan and Xiang, 2005).

In the present study, the significant increase in BMI in GDM probably favored insulin resistance, which meant that pregnant women belonged to a GDM risk group. The significantly higher age, cholesterol and triglyceride levels in patients compared to the control group, were additional factors that increased the risk for patients. Age, BMI, cholesterol and high triglycerides levels are consistent with criteria established by Carpenter and Coustan (1982) for GDM risk factors and used as parameters in the American Diabetes Association recommendations (American Diabetes Association, 2004).

There was a positive correlation between BChE activity and BMI in the GDM group, in agreement with previous studies (Alcântara et al., 2005; Randell et al., 2005; Valle et al., 2006; Das, 2007). Despite the decreased enzyme activity, the patients had significantly higher BMI and triglycerides compared to healthy pregnant women, which could explain the positive correlation between BMI and BChE activity and the absence of this correlation in pregnant women group without the disease. In addition, the negative correlation between $\mathrm{BChE}$ activity, total cholesterol and triglyceride levels observed in healthy pregnant women was usually positive. Only for HDL cholesterol, that generally correlates negatively with $\mathrm{BChE}$ activity (Randell et al., 2005; Alcântara et al., 2005; Valle et al., 2006), were the results in agreement with those for pregnant women group without GDM. In the GDM group, most of the correlations between $\mathrm{BChE}$ activity and lipoproteins reported in the literature were not observed and there was an unexpected negative correlation with LDL cholesterol (Randell et al., 2005; Alcântara et al., 2005; Valle et al., 2006; Iwasaki et al., 2007). Considering that pregnancy is an environmental stressor that changes the organisms homeostasis and that GDM promotes further changes, the unexpected correlation coefficients found between $\mathrm{BChE}$ activity and lipoproteins in pregnant women with or without GDM can be explained by the ability of pregnancy to change the relationship between $\mathrm{BChE}$ and lipid metabolism.

Even though GDM has a similar etiology to DM2, $\mathrm{BChE}$ activity behaves differently in these diseases. The determinant factor for this change is pregnancy. During healthy pregnancy, there is generally a decrease in $\mathrm{BChE}$ activity (Blitt et al., 1977; Howard et al., 1978; Whittaker, 1986), a finding corroborated here when the enzyme activity of pregnant women in the control group was compared with that of women from the general population. Wyse et al. (2004) suggest that there is a decrease in BChE activity in situations of oxidative stress, and pregnancy is considered an important environmental stressor (Robitaille and Grant, 2008).

Pregnancy results in much higher oxidative stress levels than under normal circumstances, and hyperglycemia intensifies this stress (Ramkumar et al., 2005). Orhan et al. (2003) suggested that oxidative stress accompanies complications associated with diseases such as diabetes mellitus during pregnancy. Thus, the decrease in $\mathrm{BChE}$ activity in GDM was not only due to pregnancy, but to the overall effect of pregnancy and disease. 
$\mathrm{BChE}$ activity is lower in the presence of the $-116 \mathrm{~A}$ variant (Furtado-Alle et al., 2008). As shown here, there was a significant decrease in $\mathrm{BChE}$ activity in both groups of pregnant women when $-116 G G$ was compared with $-116 A G$. It should be noted that the $-116 \mathrm{~A}$ variant and the physiology of GDM and pregnancy contribute independently to BChE activity. Pregnancy leads to a decrease in $\mathrm{BChE}$ activity and the $-116 \mathrm{~A}$ mutation, when present in this state, also decreases $\mathrm{BChE}$ activity. Although the variants $1615 \mathrm{~A}$ and $-116 \mathrm{~A}$ are in linkage disequilibrium (Souza et al., 1998), regression analysis identified only the variant $-116 \mathrm{~A}$ as an independent factor for decreasing $\mathrm{BChE}$ activity, in agreement with a study showing that the $1615 \mathrm{~A}$ enzyme is similar to the normal enzyme with regard to substrate affinity and rate of catalysis, rate of secretion and formation of tetramers, i.e., these parameters would have no effect on the structure or activity of BChE (Altamirano et al., 2000).

In conclusion, $\mathrm{BChE}$ is associated with lipid metabolism in GDM, a condition in which the activity of this enzyme is very low. Although women with GDM had significantly higher values of BMI and triglycerides, they had lower enzyme activity than healthy pregnant women, indicating that the GDM-induced decrease in BChE activity was stronger than the enhancer effect characteristic of obesity and overweight. Interestingly, the $-116 \mathrm{~A}$ variant leads to a decrease in $\mathrm{BChE}$ activity that is independent of pregnancy and GDM. Hence, each of these three factors (-116A variant, pregnancy and GDM) alters enzyme activity independently: healthy pregnant women have significantly lower BChE activity than the general population, patients with GDM have even lower activity than healthy pregnant women, and in both groups, as well as in the general population (Furtado-Alle et al., 2008), the $-116 \mathrm{~A}$ variant leads to a decrease in $\mathrm{BChE}$ activity.

\section{Acknowledgments}

This work was supported by grants and scholarships from CAPES/REUNI and Fundação Araucária.

\section{References}

Abbott CA, Mackness MI, Kumar S, Olukoga OA, Gordon C and Arrol S (1993) Relationship between serum butyrylcholinesterase activity, hypertriglyceridemia in insulin sensitivity in diabetes. Clin Sci 85:77-81.

Alcântara VM, Chautard-Freire-Maia EA, Scartezini M, Cerci MS, Braun-Prado K and Picheth G (2002) Butyrylcholinesterase activity and risk factors for coronary artery disease. Scand J Clin Lab Invest 62:399-404.

Alcântara VM, Oliveira LC, Réa RR, Suplicy HL and ChautardFreire-Maia EA (2003) Butyrylcholinesterase activity and metabolic syndrome in obese patients. Int $\mathrm{J}$ Obes Relat Metab Disord 27:1557-1564.

Alcântara VM, Oliveira LC, Réa RR, Suplicy HL and Chautard-Freire-Maia EA (2005) Butyrylcholinesterase ac- tivity and metabolic syndrome in obese patients. Clin Chem Lab Med 43:285-288.

Altamirano CV, Bartels CF and Lockridge O (2000) The butyrylcholinesterase K-variant shows similar cellular protein turnover and quaternary interaction to the wild type enzyme. J Neurochem 74:869-877.

American Diabetes Association (2004) Diagnosis and classification of diabetes mellitus. Diabetes Care 27:5-10.

Antopol W, Tuchman L and Schifrin A (1937) Cholinesterase activity of human sera with special reference to hyperthyroidism. Proc Soc Exp Biol Med 36:4650.

Babaoglu MO, Ocal T, Bayar B, Kayaalp SO and Bozkurt A (2004) Frequency and enzyme activity of the butyrylcholinesterase K-variant in a Turkish population. Eur J Clin Pharmacol 59:875-877.

Bartels CF, Van Der Spek AFL and La Du BN (1990) Two polymorphisms in the noncoding regions of the BCHE gene. Nucleic Acids Res 18:6171.

Blitt CD, Petty WC, Alberternst EE and Wright BJ (1977) Correlation of plasma cholinesterase activity and duration of action of succinylcholine during pregnancy. Anesth Analg 56:78-83.

Buchanan TA and Xiang AH (2005) Gestational diabetes mellitus. J Clin Invest 115:485-491.

Carpenter MW and Coustan DR (1982) Criteria for screening tests for gestational diabetes. Am J Obstet Gynecol 144:768-773.

Chatonnet A and Lockridge O (1989) Comparison of butyrylcholinesterase and acetylcholinesterase. Biochem J 260:625634.

Das UN (2007) Acetylcholinesterase and butyrylcholinesterase as possible markers of low-grade systemic inflammation. Med Sci Monit 13:RA214-221.

Dietz AA, Ribinstein HM, Lubrano T and Hodges LK (1972) Improved method for the differentiation of cholinesterase variants. Am J Genet 24:58-64.

Evans RT and Wroe J (1978) Is serum cholinesterase activity a predictor of succinyl choline sensitivity? An assessment of four methods. Clin Chem 24:1762-1766.

Evans RT and Wroe J (1980) Plasma cholinesterase changes during pregnancy. Their interpretation as a cause of suxamethonium-induced apnoea. Anaesthesia 35:651-654.

Furtado-Alle L, Andrade FA, Nunes K, Mikami LR, Souza RLR and Chautard-Freire-Maia EA (2008) Association of variants of the -116 site of the butyrylcholinesterase BCHE gene to enzyme activity and body mass index. Chem Biol Int 175:115-118.

Hashim Y, Shepherd D, Wiltshire S, Holman RR, Levy JC, Clark A and Cull CA (2001) Butyrylcholinesterase K variant on chromosome $3 \mathrm{q}$ is associated with type II diabetes in white Caucasian subjects. Diabetologia 44:2227-2230.

Howard JK, East NJ and Chaney JL (1978) Plasma cholinesterase activity in early pregnancy. Arch Environ Health 33:277279.

Iwasaki T, Yoneda M, Nakajima A and Terauchi Y (2007) Serum butyrylcholinesterase is strongly associated with adiposity, the serum lipid profile and insulin resistance. Intern Med 46:1633-1639.

Lahiri DK and Nurnberger Jr JL (1991) A rapid non-enzymatic method for the preparation of HMW DNA from blood for RFLP studies. Nucleic Acids Res 19:5444. 
Lepienski LM, Souza RLR, Chautard-Freire-Maia EA, Alcântara VM and Réa RR (2006) Variant K of butyrylcholinesterase and risk of early-onset type 1 diabetes mellitus in EuroBrazilians. Diabetes Obes Metab 8:709-711.

Mahmoud FF, Haines DD, Abul HT, Omu AE and Abu-Donia MB (2006) Butyrylcholinesterase activity in gestational diabetes: Correlation with lymphocyte subpopulations in peripheral blood. Am J Reprod Immunol 56:185-192.

Omu AE, Al-Azemi MK, Omu FE, Fatinikun T, Abraham S, George S and Mahnazhath N (2010) Butyrylcholinesterase activity in women with diabetes mellitus in pregnancy: Correlation with antioxidant activity. J Obstet Gynaecol 30:122-126.

Orhan H, Onderoglu L, Yücel A and Sahin G (2003) Circulating biomarkers of oxidative stress in complicated pregnancies. Arch Gynecol Obstet 267:189-195.

Pavkovic E, Simon V, Reiner E, Sucic M and Lipovac V (1993) Serum paraoxonase and cholinesterase activities in individuals with lipid and glucose metabolism disorders. Chem Biol Interact 87:179-182.

Ramkumar KM, Latha M, Ashokkumar N, Pari L and Ananthan R (2005) Modulation of impaired cholinesterase activity in experimental diabetes: Effect of Gymnema montanum leaf extract. J Basic Clin Physiol Pharmacol 16:17-35.

Randell EW, Mathews MS, Zhang H, Seraj JS and Sun G (2005) Relationship between serum butyrylcholinesterase and the metabolic syndrome. Clin Biochem 38:799-805.

Robitaille J and Grant A (2008) The genetics of gestational diabetes mellitus: Evidence for relationship with type 2 diabetes mellitus. Genet Med 10:240-250.

Schmidt MI, Duncan BB, Reichelt AJ, Branchtein L, Matos MC, E Forti AC, Spichler ER, Pousada JMDC, Teixeira MM and Yamashita T (2001) Gestational diabetes mellitus diagnosed with a $2 \mathrm{~h} 75 \mathrm{~g}$ oral glucose tolerance test and adverse pregnancy outcomes. Diabetes Care 24:1151-1155.

Schneider S, Roessli DE and Excoffier L (2000) A software for population genetics data analysis. Genetics and Biometry Laboratory, University of Geneva, Switzerland, Arlequin ver. 2.000 .

Sham PC and Curtis D (1995) Monte Carlo tests for associations between disease and alleles at highly polymorphic loci. Ann Hum Genet 59:97-105.

Siqueira MEPB, Fernícola NAGG and Borges EL (1978) Determinação de níveis normais de colinesterase plasmática e eritrocitária. Rev Saúde Públ 12:340-344.

Soreq H, Zamir R, Zevin-Sonkin D and Zakut H (1987) Human cholinesterase genes localized by hybridization to chromosomes 3 and 16. Hum Genet 77:325-328.
Souza RLR, Castro RMV, Freund A, Culpi L and Chautard-Freire-Maia EA (1998) Frequencies of the butyrylcholinesterase $\mathrm{K}$ mutation in Brazilian populations of European and African origin. Hum Biol 70:965-970.

Tham E, Liu J, Innis S, Thompson D, Gaylinn BD, Bogarin R, Haim A, Thorner MO and Chanoine JP (2009) Acylated ghrelin concentrations are markedly decreased during pregnancy in mothers with and without gestational diabetes: Relationship with cholinesterase. Am J Physiol Endocrinol Metab 296:E1093-E1100.

Vaisi-Raygani A, Rahimi Z, Entezami H, Kharrazi H, Bahrhemand F, Tavilani H, Rezaei M, Kiani A, Nomanpour B and Pourmotabbed T (2008) Butyrylcholinesterase K variants increase the risk of coronary artery disease in the population of western Iran. Scand J Clin Lab Invest 68:123-129.

Valle A, O'Connor DT, Taylor P, Zhu G, Montgomery GW, Slagboom PE, Martin NG and Whitfield JB (2006) Butyrylcholinesterase: Association with the metabolic syndrome and identification of 2 gene loci affecting activity. Clin Chem 52:1014-1020.

Whittaker M (1980) Plasma cholinesterase variants and the anaesthetist. Anesthesia 35:174-197.

Whittaker M (1986) Cholinesterase. Karger, Basel, New York, pp 65-74.

World Health Organization (1999) Report of a WHO Consultation: Aiagnosis and classification of diabetes mellitus and its complications. Department of Noncommunicable Disease Surveillance, Geneva.

World Health Organization (2006) Guidelines for the prevention, management and care of diabetes mellitus. EMRO Techn Publ Ser 32:1-82.

Wyse AT, Stefanello FM, Chiarani F, Delwing D, Wannmacher CM and Wajner M (2004) Arginine administration decreases cerebral cortex acetylcholinesterase and serum butyrylcholinesterase probably by oxidative stress induction. Neurochem Res 29:385-389.

\section{Internet Resources}

Lobato G (2002) Screening do diabetes gestacional. http://www.medcenter.com/Medscape/content.aspx? LangType $=1046 \&$ menu id $=945 \&$ id $=557 \#$ (February 27, 2013).

Sociedade Brasileira de Diabetes (2009) Diretrizes da Sociedade Brasileira de Diabetes. http://www.diabetes.org.br/attachments/diretrizes09_final.pdf. (February 27, 2013).

Associate Editor: Maria Rita Passos Bueno

All the content of the journal, except where otherwise noted, is licensed under a Creative Commons License CC BY-NC. 